ESCOM

J-CAMATD 076

\title{
An atomistic view of adhesion
}

\author{
John R. Smith ${ }^{\mathrm{a}, *}$, J.E. Raynolds ${ }^{\mathrm{b}}$, E.R. Roddick ${ }^{\mathrm{b}}$ and D.J. Srolovitz \\ a Physics Department, General Motors Research and Development Center, Warren, MI 48090-9055, U.S.A. \\ ${ }^{b}$ Department of Materials and Engineering, University of Michigan, Ann Arbor, MI 48109-2136, U.S.A.
}

Received 1 March 1996

Accepted 8 March 1996

Keywords: Adhesion; Quantum mechanics; Impurity effects; Universal behavior

\section{SUMMARY}

Some results on first-principles calculations of adhesion are reviewed. The universal relationship between adhesive energy and interfacial spacing, as well as significant effects of impurities on adhesion are discussed.

Research on the modelling of industrial materials is particularly important for the automobile industry, in which there is a rather broad spectrum of materials interests. For a recent review of automotive materials needs, see Ref. 1.

Processing and design of automotive materials often involves issues of adhesion. The nature of the strong bonds which can form between materials in intimate contact is therefore of importance. Because of the variety of materials found in these interfaces (metals, ceramics, intermetallics, and impurities), adhesion computations must be first-principles, self-consistent, quantummechanical calculations. This and the relatively low symmetry found in interfaces presents a significant challenge for computational methods.

A number of years ago, the first such adhesion computations [2] revealed an unexpected universality. We found that the total energy versus interfacial spacing for a number of different metal contacts could be simply scaled onto a single curve. Subsequently [3], we found that this universality extended to a variety of materials in adhesion, cohesion, chemisorption, and to diatomic molecules, as shown in Fig. 1.

First-principles computations were recently [4] carried out on $\mathrm{Mo} / \mathrm{MoSi}_{2}$ interfaces with and without interfacial impurities such as $\mathrm{O}, \mathrm{C}, \mathrm{B}, \mathrm{S}$, and $\mathrm{Nb}$. Again, the universal behavior was exhibited in all cases. We found that the (equilibrium) interfacial spacings increased in proportion to impurity covalent radii. All of the impurities were found to decrease the $\mathrm{Mo} / \mathrm{MoSi}_{2}$ adhesive energy, with $\mathrm{S}$ lowering it by a factor of two. Universal behavior was also found for $\mathrm{AlNi} / \mathrm{Cr}$ adhesion [5].

*To whom correspondence should be addressed. 


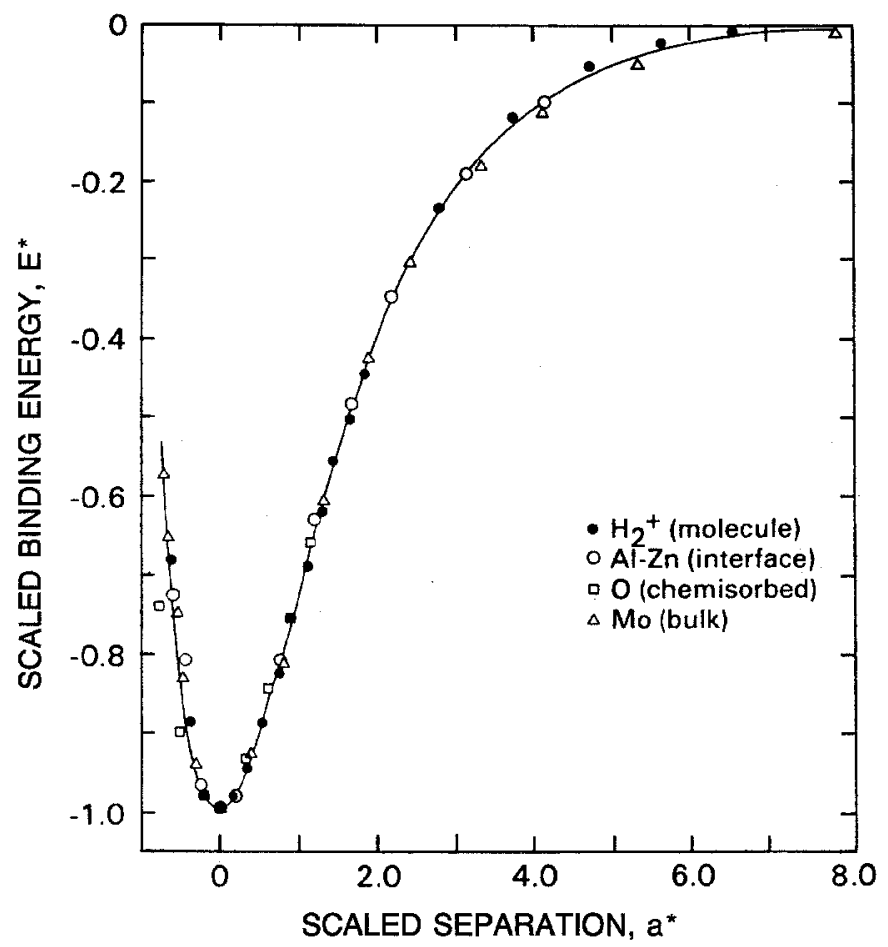

Fig. 1. Total energy versus separation for representative cases of cohesion, bimetallic adhesion, chemisorption, and a diatomic molecule, as taken from Ref. 3. The scaling of the energy and separation were taken from Ref. 3.

For a type of interface which is rather different from the metallic interfaces discussed above, we $[6,7]$ next turn to metal/ceramic interfaces. Here there is a significant ionic component to the adhesive bond, as well as a metallic/covalent component. Electron-density difference contours are shown in Fig. 2 for $\mathrm{Al} / \mathrm{MgO}$ adhesion. In Fig. 2 we plot the difference between the electrondensity distribution at large interfacial spacings and at the equilibrium spacing, respectively. The difference is nonzero only if there is an adhesive interaction. Electron-density increases are indicated by solid contours, and electron-density decreases by dashed contours. One can see that electrons tend to accumulate in the $\mathrm{Al}$ near the $\mathrm{Mg}$ ions, while there is a decrease in electron density in the $\mathrm{Al}$ near the $\mathrm{O}$ ions. Thus, the (positively charged) $\mathrm{Mg}$ ions accumulate negative charge in the metal, while the (negatively charged) $\mathrm{O}$ ions accumulate a positive charge in the metal. This is consistent with the ionic component noted above. Nevertheless, it was found that the adhesion curves for $\mathrm{MgO} / \mathrm{Al}$ and $\mathrm{MgO} / \mathrm{Ag}$ were of the same form as was obtained earlier [2-5] for bimetallic adhesion, suggesting a metallic component in the adhesive interaction. The results for $\mathrm{MgO} / \mathrm{Al}$ with and without $\mathrm{C}$ and $\mathrm{S}$ impurities are shown in Fig. 3. The curves are all of the same, simple form exhibited in Fig. 1. One can see that the curves represent well the computed points in both Figs. 1 and 3. The $\mathrm{C}$ and $\mathrm{S}$ impurities in these interfaces were found to cause substantial changes in adhesion energies, ranging from a decrease in the work of adhesion (magnitude of the minimum of the curves in Fig. 3) of over $38 \%$ for interstitial $\mathrm{S}$ to an increase of $20 \%$ for interstitial $\mathrm{C}$.

Table 1 shows our [7] results for $\mathrm{Cu} / \mathrm{Al}_{2} \mathrm{O}_{3}$ adhesion. In this case, surface relaxation of the 


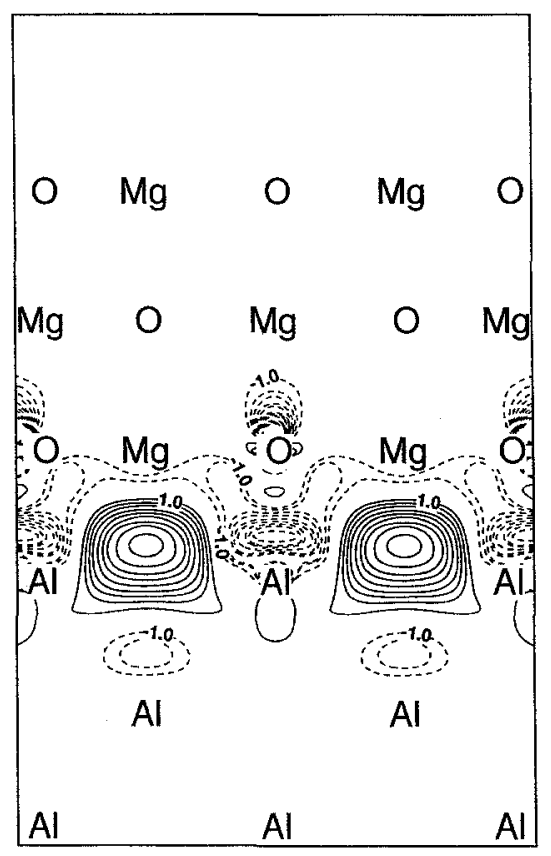

Fig. 2. Electron-density rearrangements due to adhesion between the (100) surfaces of $\mathrm{Al}$ and $\mathrm{MgO}$. These contours were determined by subtracting the electron densities of the system with the interface from that with effectively infinite separation. Solid lines (positive contours) denote electron accumulation, whereas dashed lines (negative contours) indicate electron depletion. The contour numbers are in units of $10^{-3}$ electrons/(a.u.). See Ref. 6.

$\mathrm{Al}_{2} \mathrm{O}_{3}$ changes the work of adhesion by over a factor of three. One can see also that the relaxed work of adhesion agrees reasonably well with experiment.

In conclusion, a universal behavior was found for adhesion involving metals, intermetallics, and ceramics with and without impurities. The effects of interfacial impurities were found to be substantial in all cases considered. Large relaxation effects were found for $\mathrm{Cu} / \mathrm{Al}_{2} \mathrm{O}_{3}$ adhesion.

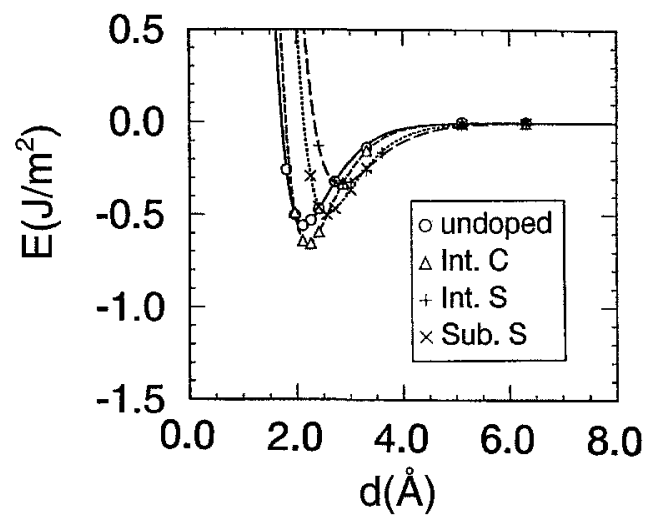

Fig. 3. Adhesive energy E versus interfacial separation d for $\mathrm{MgO} / \mathrm{Al}(001)$ with and without impurities. Results are given for interfacial monolayers of interstitial $\mathrm{C}$, interstitial $\mathrm{S}$, and substitutional $\mathrm{S}$. 
TABLE 1

ADHESION FOR $\mathrm{Cu} / \mathrm{Al}_{2} \mathrm{O}_{3}$

\begin{tabular}{ll}
\hline Method & Adhesion $\left(\mathrm{J} / \mathrm{m}^{2}\right)$ \\
\hline Unrelaxed & 2.9 \\
Relaxed & 0.9 \\
Experiment & $0.71^{\mathrm{a}}$ \\
& $0.441^{\mathrm{b}}$ \\
\hline
\end{tabular}

Taken from Ref. 8 .

b Taken from Ref. 9.

The challenge for the future is to include the plastic and elastic deformations which are known to be important in fracture, especially for metals. This will require new methods, because of the relatively large number $\mathrm{N}$ of atoms per unit cell required to represent these deformations. As the computer time of conventional quantum-mechanical methods increases as $\mathrm{N}^{3}$ for large $\mathrm{N}$, computer-time requirements for conventional methods to treat these deformations are too large. We are currently working on a new method which is linear in $\mathrm{N}$. This so-called order-N method would allow us to treat larger $\mathrm{N}$ values and perhaps initiate some investigations into affects of plastic deformations.

\section{ACKNOWLEDGEMENTS}

This work was supported in part by the U.S. Office of Naval Research, Grant N00014-91J4019. Access to computational facilities was provided by the San Diego Supercomputer Center and the National Energy Research Supercomputer Center.

\section{REFERENCES}

1 Eisenberger, P.M. (Ed.) Basic Research Needs for Vehicles of the Future, Princeton Materials Institute, Princeton University, Princeton, NJ, 1995.

2 a. Rose, J.H., Ferrante, J. and Smith, J.R., Phys. Rev. Lett., 47 (1981) 675.

b. Ferrante, J. and Smith, J.R., Phys. Rev., B31 (1985) 3427.

3 For a review, see Banerjea, A. and Smith, J.R., Phys. Rev., B37 (1988) 6632.

4 Hong, T., Smith, J.R. and Srolovitz, D.J., Phys. Rev., B47 (1993) 13615.

5 Raynolds, J.E., Smith, J.R., Roddick, E.R. and Srolovitz, D.J., Phys. Rev., B53 (1996) 13883.

6 a. Smith, J.R., Hong, T. and Srolovitz, D.J., Phys. Rev. Lett., 72 (1994) 4021.

b. Smith, J.R., Hong, T. and Srolovitz, D.J., Acta Metall. Mater., 43 (1995) 2721.

7 Zhao, G.L., Smith, J.R,, Raynolds, J. and Srolovitz, D.J., Interface Sci., 3 (1996) 289.

8 Pilliar, R.M. and Nutting, J., Phil. Mag,, 16 (1967) 181.

9 Chatain, D., Coudurier, L. and Eustathopoulos, N., Revue Phys. Appl., 23 (1988) 1055. 